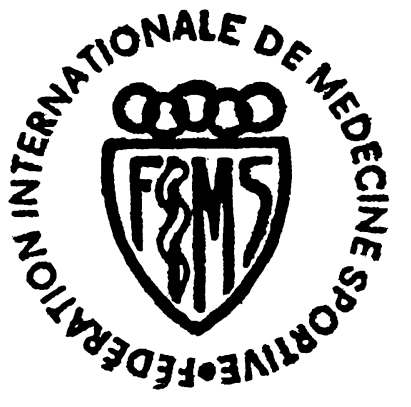

\section{THE FEDERATION INTERNATIONALE DE MEDICINE SPORTIVE}

\author{
J. G. P. WILLIAMS, MSc, FRCS, DPhysMed, Secretary General, FIMS
}

Farnham Park Rehabilitation Centre, Farnham Royal, SLOUGH SL2 3 LR

To many people the International Federation of Sports Medicine (FIMS) is something of an unknown quantity, and regrettably too often misrepresented at that. Its value is not always immediately apparent. If one were to sum its purpose and function in a single word, that word would be facilitation, since essentially the FIMS exists to facilitate the development of Sports Medicine throughout the world.

It was originally founded in 1928 as an organisation based on individual membership, but after the Second World War developed its present two tier structure. The first consists of the established National Associations of Sports Medicine throughout the world (at the present time 55) whose representatives form the governing body of the Federation or the Council of Delegates. They meet every two years and at every other meeting elect an Executive Committee and Officers. The second tier is the International College of Sports Physicians, the individual membership of the FIMS, consisting of the Honorary Members of the FIMS (individuals who have given particular service to the Federation or to iriternational sports medicine generally), the Full Members (who are medically qualified individuals or suitably qualified scientists of highest standing in one or other of the various fields of Sports Medicine and who have achieved international recognition for the specialism in their chosen field), the Associate Members (who are qualified medical practitioners who have demonstrated their own interest in Sports Medicine by completing a Basic Orientation Course in Sports Medicine approved by the Federation), and Collegiate Members (who are non-medically qualified individuals working in Sports Medicine with commensurate level of skill and expertise and who, like the Associates, have completed an appropriate course in Sports Medicine).

The FIMS has long been aware of the multi-disciplinary nature of Sports Medicine but is, and always has been, particularly concerned with its clinical aspects - hence the medical as opposed to more broadly scientific bias. This does, of course, occasionally produce problems vis-a-vis constituent national associations, but usually only at individual level.

The most obvious function of the Federation is the holding of World Congresses of Sports Medicine at which members of the International College can gather to present the results of their work and to discuss Sports Medicine in all its aspects. There is considerable argument as to whether these World Congresses should be highly scientific and esoteric occasions or whether the general approach, while maintaining academic standards, should be less sophisticated. In general the present policy is the latter since the object of the World Congress is to bring different disciplines together, accepting that each discipline will probably hold its own high scientific congress separately. The mingling of disciplines requires by contrast that the level of presentation should be more generally digestable. The General Assembly of the International College of Sports Physicians and Council of Delegates takes place at the World Congress which is now generally held every four years, i.e. in the middle of the Olympic cycle. The Federation participates in the International Sports Sciences Congress normally held in conjunction with the Olympic Games and holds its biannual Council of Delegates Meeting at that time.

The Federation has two standing Commissions: The Scientific Commission, presently chaired by Professor Strauzenberg of the German Democratic Republic, which has the task of studying any sports medicial problems referred to it by the FIMS and seeking appropriate answers for general or specific propagation. Its most important current project is the preparation of documentation on exercise and health in collaboration with the World Health Organisation and the International Society of Cardiology. It has also prepared policy statements on many difficult problems including doping, altitude and sex tests. Its main purpose is to prepare the scientific evidence upon which the FIMS as a body can act and advise.

The other standing Commission is the Inter-Federal Medical Commission, at present chaired by Dr. Albert Dirix of Belgium. This Commission consists of representatives of the medical commissions of the International Sports Federa- 
tions. Its main purpose is to look at practical medical problems which affect sport internationally with the object of standardising and regularising as far as possible common practices. It is currently involved in seeking a universal programme agreed in all sports throughout the world in relation to femininity and dope testing. It is obviously desirable that in every sport, Olympic and otherwise, in which such testing is carried out an identical protocol and system should be used in order to avoid the problems that inevitably arise where laboratories are expected to work different systems in relation to different sports. One of the future tasks of this Commission will be to seek some means of regular international policing of sportsmen in respect of, for example, the taking of anabolic steroids but this really cannot be carried out until there is international agreement as to what is or is not generally acceptable both in terms of practice and dope control.

A new Liaison Commission has recently been set up to look into relationships between the FIMS and non-medical organisations interested in the field involving the related disciplines of psychology and physical education and the professions supplementary to medicine. Consideration is also being given to the establishment of a further commission to promote Sports Medicine in developing countries.

The FIMS is also engaged in a programme of publication - the "Journal of Sports Medicine and Physical Fitness" publishes original articles and review material, together with the FIMS Bulletin; and it is the means by which the individual membership of the FIMS is kept in touch. An international Journal has peculiar problems (as indeed do all Journals of Sports Medicine) because of a tendency for most original articles to be published in specialist journals rather than in essentially multi-disciplinary journals of Sports Medicine.

The Federation's other major work is the "Basic Handbook of Sports Medicine" now published by Olympic Solidarity, the text of which was presented to the International Olympic Committee by the FIMS at the Olympic Games in Montreal. It seals an agreement that the educational programme in sports medicine sponsored by Olympic Solidarity will be carried out only in collaboration with the FIMS. Thus international courses of Sports Medicine sponsored by Olympic Solidarity (such as that held in India in November 1979) are carried out under the exclusive aegis of the FIMS, which itself also organises basic orientation courses in Sports Medicine in a variety of countries according to need - the previous one being held in Thailand in November 1978.

Olympic Solidarity is a department of the International Olympic Committee funded from royalties paid by the media in respect of broadcasts of the Olympic Games. It disperses financial aid to the development of sport throughout the World, particularly in developing countries, usually by arranging courses, lectures and other forms of teaching.

In addition the FIMS recognises suitable National Courses as leading to Associate Membership of the FIMS (for example that recently held in the German Democratic Republic). The FIMS is sometimes criticised in respect of its attitude to these courses but it must be remembered that a world-wide organisation of an essentially democratic nature must apply its rules evenly. This may at times be irksome to the more sophisticated National Associations and there have from time to time been temporary defections (usually because some individual in the National Association concerned has felt himself somehow slighted!). Inevitably, however, these problems have proved no more than temporary "hiccups".

Some may ask "What is in it for me?". The answer is dependent on how much one is prepared to put in. Membership of the FIMS offers the opportunity of contact with a wide variety of different people throughout the world in the disciplines of Sports Medicine. This contact is made on a personal basis at congresses of Sports Medicine whether organised and run by the FIMS or in conjunction with it. The FIMS, through its Directory and through the Bulletins published regularly in its Journal, keeps all members informed of what is going on in the world of Sports Medicine, particularly from an organisational and political point of view. Clinical and scientific material is also promulgated through the Journal, although it is expected that most members of the Federation will be taking their own National journal and maybe others as well.

For those who wish to involve themselves further, there is an opportunity to participate in the affairs of the Federation, initially through its commissions and to a degree also through membership of the Council of Delegates (as a National Delegate), and of the Executive body. The interested and energetic individual will have ample scope to exercise his talents in teaching, organisation and administration. Other "perks", such as foreign travel and the chance to visit new places will almost invariably follow. Above all, however, the International Federation of Sports Medicine gives to its members the priceless opportunity of new friends, new outlooks on life and a wider and more satisfying experience of Sports Medicine generally. 